\section{GBT440 inhibits sickling of sickle cell trait blood under in vitro conditions mimicking strenuous exercise}

\author{
Kobina Dufu, Josh Lehrer-Graiwer, \\ Eleanor Ramos, Donna Oksenberg \\ Global Blood Therapeutics Inc., San \\ Francisco, CA, USA
}

\section{Abstract}

In sickle cell trait (SCT), hemoglobin A $(\mathrm{HbA})$ and $\mathrm{S}(\mathrm{HbS})$ are co-expressed in each red blood cell (RBC). While homozygous expression of $\mathrm{HbS}(\mathrm{HbSS}$ ) leads to polymerization and sickling of RBCs resulting in sickle cell disease (SCD) characterized by hemolytic anemia, painful vaso-occlusive episodes and shortened life-span, SCT is considered a benign condition usually with minor or no complications related to sickling. However, physical activities that cause increased tissue oxygen demand, dehydration and/or metabolic acidosis leads to increased $\mathrm{HbS}$ polymerization and life-threatening complications including death. We report that GBT440, an agent being developed for the treatment of SCD, increases the affinity of oxygen for $\mathrm{Hb}$ and inhibits in vitro polymerization of a mixture of $\mathrm{HbS}$ and HbA that simulates SCT blood. Moreover, GBT440 prevents sickling of SCT blood under in vitro conditions mimicking strenuous exercise with hypoxia, dehydration and acidosis. Together, our results indicate that GBT440 may have the potential to protect SCT individuals from sickling-related complications during conditions that favor $\mathrm{HbS}$ polymerization.

\section{Introduction}

Sickle cell trait (SCT) is characterized by the inheritance of normal and sickle -globin alleles resulting in the expression of both hemoglobin $\mathrm{A}(\mathrm{HbA})$ and $\mathrm{S}(\mathrm{HbS})$ in red blood cells (RBCs). It is estimated that 300 million people worldwide have SCT, with the highest prevalence of approximately 30 to $40 \%$ in subSaharan Africa. ${ }^{1}$ A complex and potentially lifethreatening pathophysiology is usually linked to the expression of $\mathrm{HbS}$ due to polymerization of deoxygenated $\mathrm{HbS}$ (deoxy-HbS) which causes sickling and damage of RBCs. For example, in sickle cell disease (SCD) where both alleles of the $\beta$-globin gene carry the sickle mutation, $\mathrm{HbS}$ constitutes almost all of the total $\mathrm{Hb}$ expressed within RBCs. As a consequence, polymerization of deoxy-HbS and sickling of
RBCs occurs frequently leading to occlusion of tissue capillaries, hemolytic anemia, ischemic tissue injury, progressive end organ damage and premature death in SCD. ${ }^{2}$ In contrast to SCD, SCT is not viewed as a disease state because its complications are minor or rare. ${ }^{1,3,4}$ With typically $<1 \%$ circulating sickled RBCs, SCT individuals rarely experience complications related to sickling. ${ }^{5}$ These benign clinical observations are most likely attributed to the significant expression of $\mathrm{HbA}$ within RBCs. On the average, $\mathrm{HbA}$ accounts for $\sim 60 \%$ of the total hemoglobin expressed in SCT RBCs. ${ }^{1} \mathrm{HbA}$ inhibits polymerization of deoxy$\mathrm{HbS}$, thus minimizing sickling and related complications. ${ }^{6}$ However, activities or processes that causes hypoxia, dehydration, acidosis, hypothermia, increased RBC 2.3-DPG concentration and hyperosmolality of blood can increase sickling in SCT individuals. ${ }^{1,7}$ For example, strenuous exercise (especially at high altitudes) induces severe hypoxemia, metabolic acidosis, hyperthermia, and red-cell dehydration, all of which promote exertional sickling resulting in serious morbidity.,3,8-10 Exertional sickling and rhabdomyolysis have potentially led to the sudden death of soldiers and athletes with SCT. ${ }^{11-13}$ Other sickling related complications include splenic infarction, exertional heat illness (heat stroke and renal failure), increased urinary tract infections in women, gross hematuria, hyposthenuria, and hyphemia. ${ }^{3,10}$ Thus, although SCT is generally considered benign, it is important to manage $\mathrm{HbS}$ polymerization and sickling in SCT individuals during strenuous physical exertion or under conditions that promote sickling-related complications. Currently, there is no therapeutic option to prevent sickling-related complications in SCT.

GBT440, an allosteric modifier of $\mathrm{Hb}$ oxygen $\left(\mathrm{Hb}-\mathrm{O}_{2}\right)$ affinity, is a novel anti-sickling agent that is being developed for the treatment of SCD. ${ }^{14}$ GBT440 increases $\mathrm{Hb}-\mathrm{O}_{2}$ affinity, delays polymerization of deoxy-HbS and prevents in vitro sickling of sickle RBCs (SSRBCs). ${ }^{14}$ In this study, we show that GBT440 inhibits polymerization of a mixture of $\mathrm{HbS}$ and $\mathrm{HbA}$. In addition, we demonstrate that GBT440 prevents sickling of SCT blood under in vitro conditions mimicking strenuous exercise with hypoxia, dehydration and acidosis. Together, our results suggest that GBT440 may have the potential to protect SCT individuals from sickling-related complications during conditions that favor $\mathrm{HbS}$ polymerization.

\section{Materials and Methods}

\section{Blood source}

Sodium citrate anticoagulated whole blood from sickle cell patients was obtained from
Correspondence: Kobina Dufu, Global Blood Therapeutics, 400 East Jamie Court, suite 101, South San Francisco, CA 94080.

Tel: +1.650 .741 .7722 . Fax: +1.650 .741 .7701 . E-mail: kdufu@globalbloodtx.com

Key words: Sickle cell trait; sickle cell disease; exertional sickling; rhabdomylosis; hemoglobin oxygen affinity.

Contributions: KD, conceived of the study, conducted experiments, interpreted and discussed data, prepared the figures and wrote the manuscript; JLG and ER, interpreted and discussed data and contributed significantly towards manuscript preparation; D0, provided data interpretation, discussion and study oversight.

Conflict of interest: Kobina Dufu, Josh LehrerGraiwer, Eleanor Ramos and Donna Oksenberg are current employees and shareholders of Global Blood Therapeutics, Inc.

Aknowledgements: we will like to acknowledge the University of North Carolina Comprehensive Sickle Cell Program (UNC, Chapel Hill, NC) for providing blood from sickle cell patients. We would also like to thank Mira Patel for coordinating supply of blood for this study, Zhe Li and Qing $\mathrm{Xu}$ for providing compound and Uma Sinha for useful discussions.

Received for publication: 3 June 2016.

Accepted for publication: 30 August 2016.

This work is licensed under a Creative Commons Attribution-NonCommercial 4.0 International License (CC BY-NC 4.0).

(C) Copyright K. Dufu et al., 2016

Licensee PAGEPress, Italy

Hematology Reports 2016; 8:6637

doi:10.4081/hr.2016.6637

University of North Carolina Comprehensive Sickle Cell Program with Institutional Review Board approval. Sodium citrate anticoagulated whole blood from sickle trait donors was obtained from Conversant Bio, Inc.

\section{Buffers}

i) Hemox buffer (30 mM TES, $130 \mathrm{mM} \mathrm{NaCl}, 5$ $\mathrm{mM} \mathrm{KCl})$

ii) $10 \mathrm{mM}$ Potassium phosphate buffer $(\mathrm{pH}$ $7.4,111 \mathrm{mM} \mathrm{NaCl}$ ), ionic strength 0.137

iii) $10 \mathrm{mM}$ Potassium phosphate buffer $(\mathrm{pH}$ $6.9,179 \mathrm{mM} \mathrm{NaCl}$ ), ionic strength 0.2

Preparation of purified hemoglobin $\mathrm{S}$ and hemoglobin $\mathrm{A}$ for polymerization

Gel filtration and DE-52 anion exchange chromatography were used to purify $\mathrm{HbS}$ or $\mathrm{HbA}$ from sickle cell or normal donor RBC lysates, respectively. ${ }^{15}$ Samples of the eluted fractions 
were run on a Tris-glycine $12 \%$ acrylamide native gel where they were separated according to their isoelectric point allowing for their identification. Purified $\mathrm{HbS}$ or $\mathrm{HbA}$ was buffer exchanged into $1.8 \mathrm{M} \mathrm{KH}_{2} \mathrm{PO}_{4}$ at $\mathrm{pH} 7.4$, flash frozen with liquid nitrogen and stored at $-80^{\circ} \mathrm{C}$.

\section{In vitro polymerization}

$\mathrm{HbS}$ polymerization was evaluated in an adapted version of the in vitro polymerization assay described by Adachi and colleagues (1982). For all polymerization experiments, 50 $\mu \mathrm{M}$ of $\mathrm{Hb}(\mathrm{HbS}$ alone or mixture of $\mathrm{HbS}$ and $\mathrm{HbA}$ ) in $1.8 \mathrm{M} \mathrm{KH}_{2} \mathrm{PO}_{4}$ at $\mathrm{pH} 7.4$ was used. To evaluate the ability of GBT440 to delay polymerization, $\mathrm{HbS}$ was first incubated with GBT440 [prepared in 100\% dimethyl sulfoxide (DMSO)] for $1 \mathrm{~h}$ at $37^{\circ} \mathrm{C}$. The final DMSO concentration was $0.3 \%$. The Hb solution was deoxygenated in a hypoxic chamber $(99.5 \%$ $\mathrm{N}_{2} / 0.5 \% \mathrm{O}_{2}$ ) for $90 \mathrm{~min}$ at $4^{\circ} \mathrm{C}$ and polymerization was initiated by increasing the temperature from 4 to $37^{\circ} \mathrm{C}$. Polymerization was measured by the increase in absorbance at $700 \mathrm{~nm}$ for $50 \mathrm{~min}$. A plot of the optical density (at 700 $\mathrm{nm})$ on the $y$-axis against time on the $\mathrm{x}$-axis was generated. The delay time was determined as the timepoint at which the derivative (or slope) of the polymerization curve was equal to +0.02 (a positive slope signifying the point of inflection from the delay phase to the polymer growth phase of the curve).

\section{In vitro sickling of isolated red blood cells}

Whole blood $(500 \mu \mathrm{L})$ from SCT individuals or SCD patients was added to $500 \mu \mathrm{L}$ of poly(butylene succinate) (PBS) $(\mathrm{pH} 7.4)$ and centrifuged (Eppendorf $5430 \mathrm{R}$ centrifuge) at $250 \mathrm{~g}$ for $5 \mathrm{~min}$. After centrifugation, the supernatant was discarded. This process was repeated twice after which the resulting packed RBCs (100\% Hct) were used for sickling experiments. GBT440 (prepared in 100\% DMSO) was added to $40 \mu \mathrm{L}$ of PBS at a final concentration of $1 \mathrm{mM}$. The final DMSO concentration was $0.5 \%$. Next, $10 \mu \mathrm{L}$ of isolated RBCs was added to the PBS to a final Hct of $20 \%$, immediately mixed by pipetting and incubated at radiotherapy (RT) for $30 \mathrm{~min}$ or $1 \mathrm{~h}$. The $\mathrm{RBC} /$ compound reaction mixture was transferred to a 96-well gas permeable plate (cat \#8602001, Coy Laboratory Products) and incubated for $0.5 \mathrm{~h}$ at $37^{\circ} \mathrm{C}$ in a humidified hypoxic chamber $\left(96 \% \mathrm{~N}_{2} / 4 \% \mathrm{O}_{2}\right)$. Next, $5 \mu \mathrm{L}$ of the reaction mixture was added to deoxygenated PBS $(200 \mu \mathrm{L})$ in a 24 -well plate and imaged using a microscope (40× magnification) in the humidified hypoxic chamber. Images were quantitated by manually counting round (unsickled) versus non-round (sickled) or based on circularity using the CellVigene software (VigeneTech, Inc.) designed to quantify sickling.

\section{Whole blood oxygen equilibrium curves and sickling}

Oxygen equilibrium curves (OECs) were determined with a Hemox analyzer (TCS Scientific). Whole blood samples were incubated for $1 \mathrm{~h}$ at $37^{\circ} \mathrm{C}$ with various concentrations of GBT440 followed by transfer to the sample chamber of the Hemox analyzer. The samples were first saturated with compressed air and then flushed with pure nitrogen to deoxygenate. The absorbance at wavelengths that correspond to the isosbestic point $(570 \mathrm{~nm})$ and deoxy-Hb $(560 \mathrm{~nm})$ were recorded as a
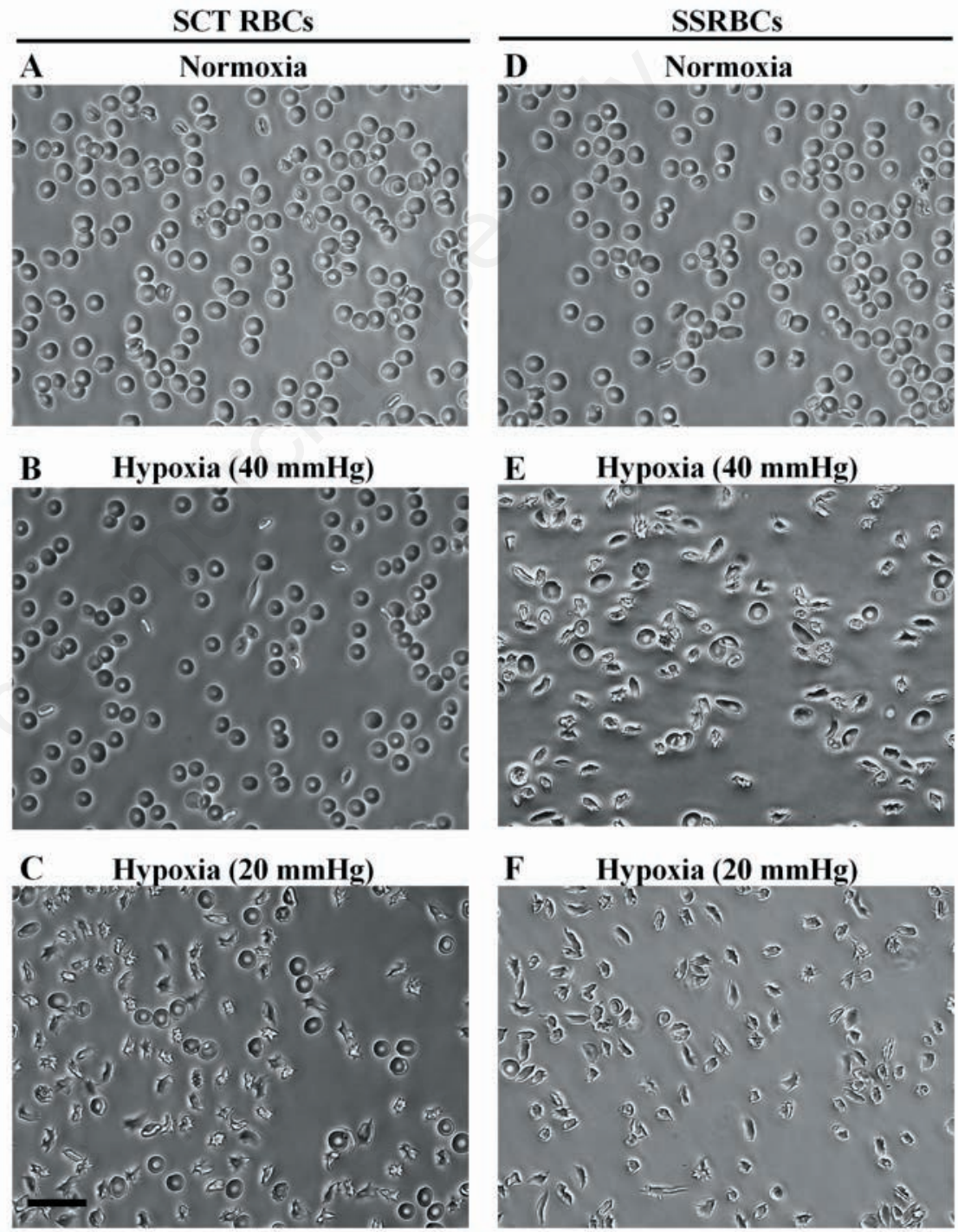

\section{Scale bar $=30 \mu \mathrm{m}$}

Figure 1. Isolated sickle cell trait (SCT) red blood cells (RBCs) sickle under severe hypoxic conditions. A) and D) Representative images of SCT RBCs and sickling of sickle RBCs (SSRBCs) incubated under normoxia, respectively. B) and C) Representative images of SCT RBCs incubated under $40 \mathrm{~mm} \mathrm{Hg}$ (resting hypoxia) and $20 \mathrm{~mm} \mathrm{Hg}$ (severe hypoxia), respectively. E) and F) Similar to $B$ and $C$ except images represent SSRBCs. 


\section{Results}

Isolated sickle cell trait red blood cells sickle under severe hypoxic conditions

We previously showed that SSRBCs when incubated for $0.5 \mathrm{~h}$ under hypoxic conditions mimicking resting hypoxia $\mathrm{pO}_{2}$ of $40 \mathrm{~mm}$ $\mathrm{Hg}){ }^{14}$ During strenous exercise the $\mathrm{pO}_{2}$ in metabolically active tissues may decrease below $40 \mathrm{~mm} \mathrm{Hg}$, a condition we define as severe hypoxic condition. ${ }^{16}$ To demonstrate the difference in sickling under resting and severe hypoxic conditions, we incubated SCT RBCs and SSRBCs at 40 or $20 \mathrm{~mm} \mathrm{Hg}$ for $0.5 \mathrm{~h}$. In ambient air (normoxia), both SCT RBCs and SSRBCs were mostly un-sickled (Figure 1A, D). When incubated under resting $(40 \mathrm{~mm} \mathrm{Hg})$ or severe (20 mm $\mathrm{Hg}$ ) hypoxic conditions, SSRBCs sickled extensively (Figure 1E, F). In contrast, SCT RBCs only sickled when incubated under severe hypoxic conditions (Figure 1C) but not under resting hypoxic conditions (Figure 1B).

GBT440 delays polymerization of a mixture of $60 \%$ hemoglobin $A$ and $40 \%$ hemoglobin S

The tendency of a RBC to sickle in vivo is fundamentally a kinetic phenomenon controlled by polymerization delay time of deoxy$\mathrm{HbS}$ relative to $\mathrm{RBC}$ transit time through hypoxic tissue capillaries. ${ }^{17}$ Polymerization of deoxy-HbS begins with a striking latency period (delay time) followed by abrupt polymer formation. ${ }^{18,19}$ Since deoxy-HbS polymers melt
$-100 \% \mathrm{HbS}$

- $60 \% \mathrm{HbA} / 40 \% \mathrm{HbS}$

- $60 \% \mathrm{HbA} / 40 \% \mathrm{HbS}$; GBT440

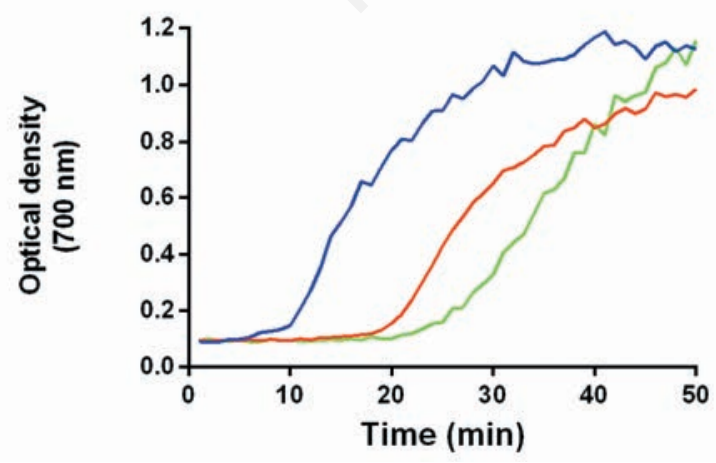

Figure 2. GBT440 delays polymerization of sickle cell trait hemoglobin $(\mathrm{Hb})$ mixture $(60 \% \mathrm{HbA} / 40 \% \mathrm{HbS})$. The optical density at $700 \mathrm{~nm}$ measures turbidity of the $\mathrm{Hb}$ solution which represents polymerization of $\mathrm{HbS}$. The final concentration of Representative curves of $n=3$ are shown. GBT440 and total $\mathrm{Hb}$ were $100 \mu \mathrm{M}$ and $50 \mu \mathrm{M}$, respectively. when exposed to an oxygenated environment (such as in the lungs), the highest susceptibility of sickling is during $\mathrm{RBC}$ transit through hypoxic tissue capillaries. ${ }^{17,18}$ Thus, when the delay time is longer than RBC transit time through hypoxic tissue capillaries, RBCs do not sickle during circulation. ${ }^{6,17}$ Non-polymerizable $\mathrm{HbA}$ delays polymerization of deoxy- $\mathrm{HbS}$ by virtue of dilution. ${ }^{15}$ However, deoxy-HbA and -HbS hybrids ( $\mathrm{Hb} \mathrm{A} / \mathrm{S}$ ) can copolymerize to some extent with deoxy-HbS and shorten polymerization delay times, consequently removing the full inhibitory benefit of HbA. ${ }^{15,20}$ GBT440 delays polymerization of deoxy-HbS by increasing the fraction of oxygenated-HbS (oxy-HbS) during deoxygenation. ${ }^{14}$ Since oxy$\mathrm{Hb}$ (oxy-HbA, oxy-HbS or oxy-Hb A/S hybrid) inhibits deoxy-HbS polymerization, we tested the ability of GBT440 to delay in vitro polymerization of a mixture of $60 \% \mathrm{HbA}$ and $40 \% \mathrm{HbS}$, which simulates typical SCT Hb mixture. Compared to $100 \% \mathrm{HbS}$ which exhibited a delay time of $9 \mathrm{~min}$, the delay time for the $\mathrm{HbA} / \mathrm{HbS}$ mixture was $19 \mathrm{~min}$ (Figure 2). GBT440 increased the polymerization delay time of the $\mathrm{HbA} / \mathrm{HbS}$ mixture from 19 to 25 min. Thus, these data demonstrate that GBT440 can extend the polymerization delay

GBT440 prevents sickling of sickle cell trait blood under severe hypoxic conditions

Since GBT440 can delay polymerization of a SCT mixture of $60 \% \mathrm{HbA}$ and $40 \% \mathrm{HbS}$, we investigated whether GBT440 could inhibit sickling of SCT blood under severe hypoxic conditions. For the sickling assay previously described (Figure 1), isolated SCT RBCs were incubated without agitation and under fixed hypoxic conditions for $0.5 \mathrm{~h}$, which is a much longer duration than typical RBC transit times ( $<1 \mathrm{~min}$ ) through hypoxic tissue capillaries and venous circulation. ${ }^{17}$ For a more physiologtime of a SCT mixture of $\mathrm{HbA}$ and $\mathrm{HbS}$ in vitro.

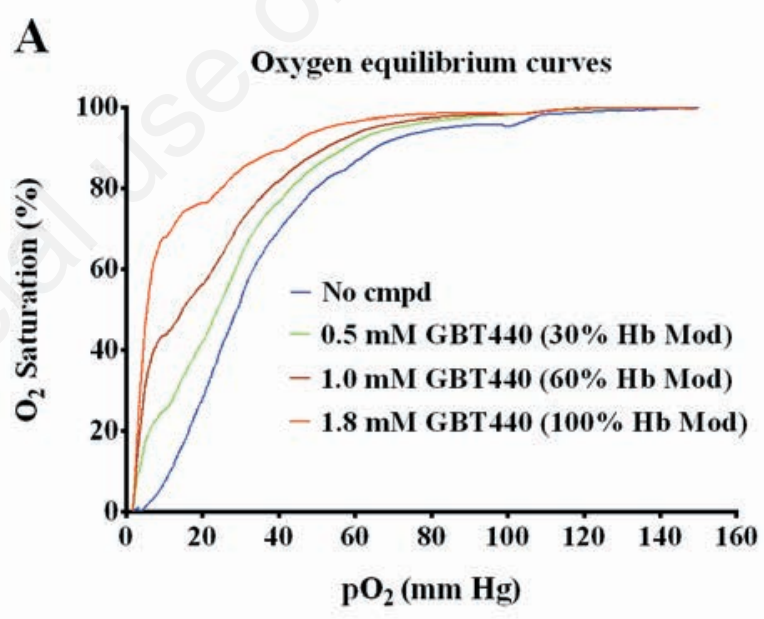

B In vitro sickling of SCT blood

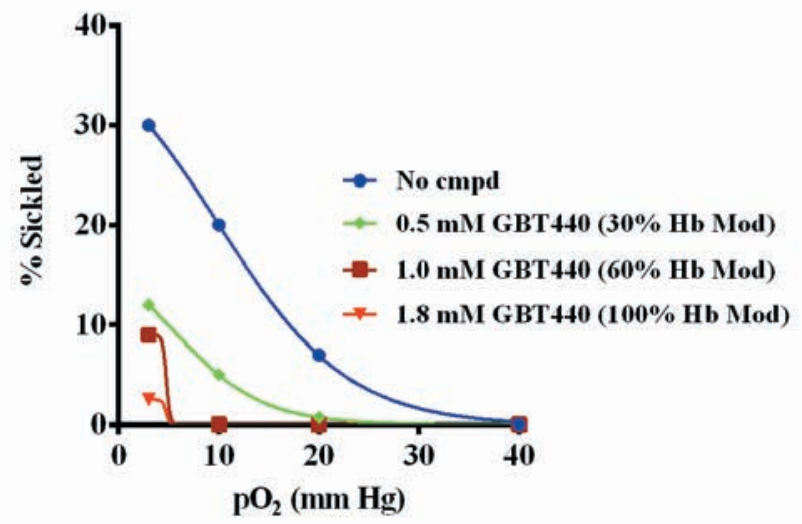

Figure 3. GBT440 inhibits in vitro sickling of sickle cell trait (SCT) blood under extreme hypoxia. A) Oxygen equilibrium curves (OECs) of SCT blood treated in vitro with varying concentrations of GBT440. B) Percentage of sickled SCT red blood cells at the indicated oxygen tensions corresponding to the OECs in A. SCT blood ( $n=1$ sample) at $36 \% \mathrm{Hct}(\sim 1.8 \mathrm{mM}$ of hemoglobin) was used. 
ically relevant scenario, we determined the anti-sickling activity of GBT440 in SCT blood under variable hypoxic conditions over a shorter duration of time. In vitro sickling of SCT blood was evaluated in a Hemox analyzer followed by morphometric measurements. Using the Hemox analyzer, SCT blood was deoxygenated from $150 \mathrm{~mm} \mathrm{Hg}$ to $1.6 \mathrm{~mm} \mathrm{Hg}$ within $\sim 10$ min, such that on the average, SCT RBCs were exposed to each oxygen tension for less than a minute. During deoxygenation, SCT RBCs were harvested at oxygen tensions of $150,100,40,20,10$ and $3 \mathrm{~mm} \mathrm{Hg}$ and fixed with $2 \%$ glutaraldehyde. We observed relatively much less sickling of SCT RBCs under severe hypoxia using this method compared to the previous method used in Figure 1 (data not shown), most likely reflecting the difference in duration of deoxygenation in the two assays. To evaluate the antisickling effect of GBT440, SCT blood (36\% Hct, $\sim 1.8 \mathrm{mM} \mathrm{Hb}$ ) was incubated with various concentrations of GBT440 for $1 \mathrm{~h}$ prior to deoxygenation in the Hemox analyzer. The X-ray structure of GBT440 bound to $\mathrm{HbS}$ suggests that GBT440 binds in a 1:1 ratio to $\mathrm{Hb}$ tetramer. ${ }^{14}$ Assuming all of GBT440 is available to bind $\mathrm{Hb}$ in the context of the RBC, then GBT440 concentrations of $0.5,1.0$ and $1.8 \mathrm{mM}$ correspond to a calculated $\mathrm{Hb}$ modification (\%HbMod) of 30,60 and $100 \%$, respectively. GBT440 produced a concentration-dependent left shift in the OEC relative to untreated SCT blood indicating that GBT440 increased the $\mathrm{Hb}-\mathrm{O}_{2}$ affinity of SCT blood (Figure 3A). Moreover, GBT440 reduced the percentage of sickled SCT RBCs relative to untreated control during deoxygenation (Figure 3B). Of note, at $20 \mathrm{~mm} \mathrm{Hg}, 30 \% \mathrm{HbMod}$ with GBT440, which was well tolerated in both healthy subjects and SCD patients in a Phase1/2 clinical trial (NCT02285088), was sufficient to prevent sickling in contrast to the untreated control SCT blood which had 7\% sickled RBCs. These data show that GBT440 inhibits sickling of SCT RBCs under extreme hypoxic conditions in vitro and suggest that GBT440 may have the potential to reduce exertional sickling in SCT individuals. Unlike SCD, where patients are usually anemic and have reduced hematocrits ( $\sim 20 \% \mathrm{Hct})$, SCT individuals have normal hematocrits ( $>35 \%$ Hct), thus $7 \%$ sickled cells represents a relatively larger number of circulating sickled cells in SCT compared with SCD.

\section{GBT440 inhibits sickling of sickle cell trait blood under conditions mimicking a combination of hypox- ia, dehydration and acidosis}

As previously mentioned, the difference in the ability of SSRBCs and SCT RBCs to sickle reflects the difference in their respective pathophysiology. Strenuous exercise at higher altitudes where the fraction of inspired oxygen is less than at sea level $\left(\sim 21 \% \mathrm{O}_{2}\right.$ or $>105 \mathrm{~mm}$ $\mathrm{Hg}$ ) induces severe hypoxemia, metabolic acidosis, hyperthermia, and red-cell dehydration, all of which are conditions that lead to increased sickling of SCT RBCs. We next evaluated whether GBT440 could inhibit sickling of SCT blood under conditions mimicking a combination of hypoxia, dehydration and acidosis. Sickling of SCT blood was measured in hypertonic phosphate buffer at a $\mathrm{pH}$ of 6.9 to mimic extreme dehydration and acidosis under hypoxic conditions in the Hemox analyzer. As shown in Figure 4A, the OEC of SCT blood suspended in hypertonic phosphate buffer $(\mathrm{pH}$ 6.9 ) is right-shifted relative to isotonic phosphate buffer ( $\mathrm{pH} 7.4)$. The right-shift in the OEC is attributed to the decrease in $\mathrm{pH}$ from 7.4 to 6.9 indicating a decrease in $\mathrm{Hb}-\mathrm{O}_{2}$ affinity in response to increased $\mathrm{H}+$ ion concentration, a phenomenon referred to as the Bohr effect. ${ }^{21}$ Compared to normal $\mathrm{pH}$ conditions (pH 7.4), more deoxy-HbS molecules are formed at every level of hypoxia under lower or more acidic $\mathrm{pH}$ conditions which leads to increased polymerization and sickling. In addition, RBCs dehydrate when suspended in a hypertonic medium. Dehydration reduces the RBC volume due to loss of water and as a result
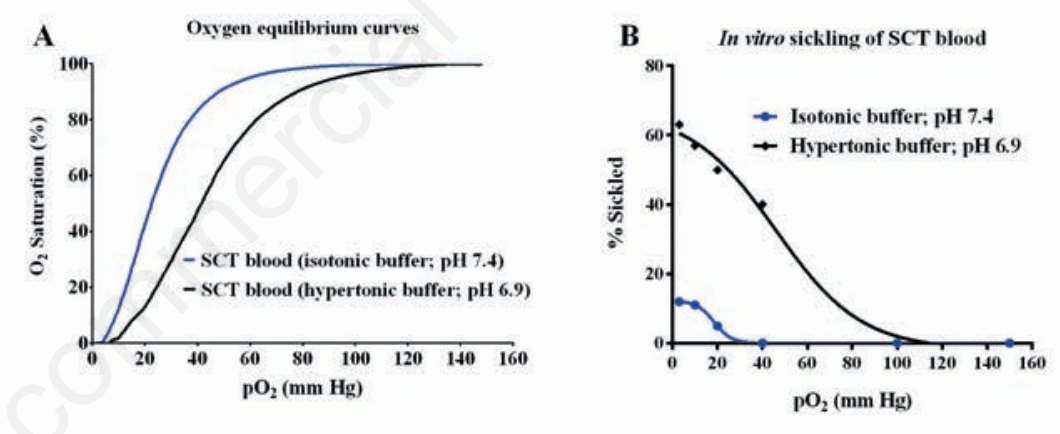

C

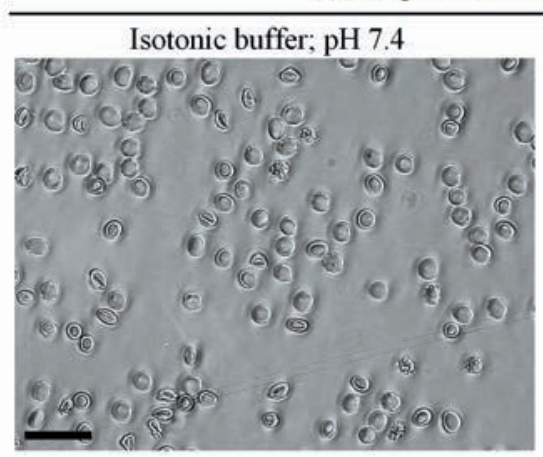

Sickling of SCT blood at $20 \mathrm{~mm} \mathrm{Hg}$

Although SCT is considered a benign condition, activities such as strenuous exercise can

Scale bar $=30 \mu \mathrm{m}$

Figure 4. Sickle cell trait (SCT) red blood cells (RBCs) sickle more frequently under conditions mimicking a combination of hypoxia, dehydration and acidosis in vitro. A) Oxygen equilibrium curves (OECs) of SCT blood (30\% Hct $1.5 \mathrm{mM}$ hemoglobin) in isotonic phosphate buffer ( $\mathrm{pH} 7.4)$ or hypertonic phosphate buffer ( $\mathrm{pH}$ 6.9). B) Percentage of SCT RBCs sickled at the indicated oxygen tensions corresponding to the OECs in (A). C) Representative images SCT RBC sickling in isotonic phosphate buffer (pH 7.4) or hypertonic phosphate buffer ( $\mathrm{pH}$ 6.9). 

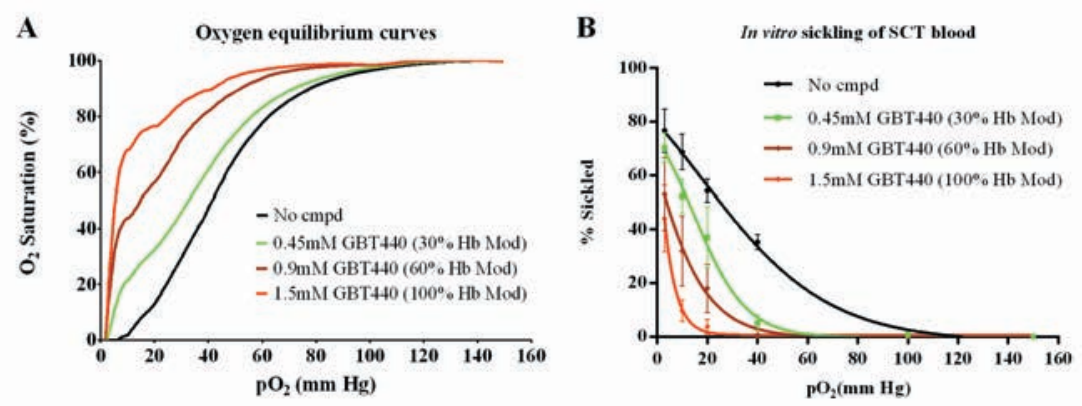

Figure 5. GBT440 inhibits in vitro sickling of sickle cell trait (SCT) red blood cells (RBCs) under conditions mimicking a combination of hypoxia, dehydration and acidosis. A) Oxygen equilibrium curves (OECs) of SCT blood treated with varying concentrations of GBT440 in hypertonic phosphate buffer, $\mathrm{pH}$ 6.9. B) Percentage of sickled SCT RBCs at the indicated oxygen tensions corresponding to the OECs in (A). Mean and standard error of mean shown for $n=3$ SCT donors.

lead to sickling-related complications, including death. 1,23 There is currently no therapeutic option to manage or prevent sickling-related complications in SCT. In this study, we determined the ability of GBT440, a molecule that is being developed for the treatment of SCD, to inhibit in vitro sickling of SCT RBCs under various conditions. We found that SCT RBCs remain unsickled under resting hypoxic conditions but sickled under severe hypoxic conditions. While the duration of exposure of SCT RBCs to hypoxia in this experiment is nonphysiological, the results are consistent with the observation that under normal circumstances (such as at rest or during mild exercise), SCT individuals do not experience significant RBC sickling events but may do so under stressful conditions such as during strenuous exercise at high altitude. ${ }^{8}$ These data also suggest that under stressed conditions, $\mathrm{HbA}$ alone may not be enough to inhibit polymerization of deoxy-HbS in SCT RBCs. Under more physiologically relevant temporal/deoxygenation conditions, sickling of SCT RBCs increased with increasing hypoxia even though the level of sickling was relatively low compared to that of SCD blood under the same conditions. Nevertheless, GBT440 dose-dependently reduced the number of sickled SCT RBCs under all levels of hypoxia evaluated.

In SCT, renal abnormalities are among the most common complications. 1,3 The renal medulla of the kidneys is an acidotic environment characterized with low oxygen tension and high interstitial osmolality. ${ }^{3}$ Extensive sickling may cause vaso-occlusion and medullary microinfarctions. ${ }^{3}$ Additionly, strenuous physical exertion at high altitudes may induce severe hypoxemia, metabolic acidosis, hyperthermia, and or red-cell dehydration, all of which promote exertional sickling potentially leading to serious morbidity. $3,4,8-10$ We determined the ability of SCT RBCs to sickle under in vitro conditions of hypoxia, acidosis and dehydration. The results showed that SCT RBCs sickled more readily and extensively under these conditions and GBT440 reduced sickling in a dose-dependent manner. Together, these data demonstrate that GBT440 may have the potential to prevent in vivo sickling and sickling-related complications under strenuous conditions in individuals with sickle cell trait.

\section{References}

1. Tsaras G, Owusu-Ansah A, Boateng FO, Amoateng-Adjepong Y. Complications associated with sickle cell trait: a brief narrative review. Am J Med 2009;122:507-12.

2. Kaul DK. Vascular obstruction in sickle cell disease. J Biol Med 2001;156-63.

3. John $\mathrm{N}$. A review of clinical profile in sick le cell traits. Oman Med J 2010;25:3-8.

4. Connes P, Harmon KG, Bergeron MF. Pathophysiology of exertional death associated with sickle cell trait: can we make a parallel with vaso-occlusion mechanisms in sickle cell disease? Br J Sports Med 2013;47:190.

5. Goldsmith JC, Bonham VL, Joiner CH, et al. Framing the research agenda for sickle cell trait: building on the current understanding of clinical events and their potential implications. Am J Hematol 2012;87: 340-6.

6. Mozzarelli A, Hofrichter J, Eaton WA. Delay time of hemoglobin $\mathrm{S}$ polymerization prevents most cells from sickling in vivo. Science 1987;237:500-6.

7. Key NS, Derebail VK. Sickle-cell trait: novel clinical significance. Hematology Am Soc Hematol Educ Program 2010;2010:418-22.
8. Martin TW, Weisman IM, Zeballos RJ, Stephenson SR. Exercise and hypoxia increase sickling in venous blood from an exercising limb in individuals with sickle cell trait. Am J Med 1989;87:48-56.

9. Bergeron MF, Cannon JG, Hall EL, Kutlar A. Erythrocyte sickling during exercise and thermal stress. Clin J Sport Med 2004;14: 354-6.

10. Mitchell BL. Sickle cell trait and sudden death-bringing it home. J Natl Med Assoc 2007;99:300-5.

11. Van Camp SP, Bloor CM, Mueller FO, et al. Nontraumatic sports death in high school and college athletes. Med Sci Sports Exerc 1995;27:641-7.

12. Gardner JW, Kark JA. Fatal rhabdomyolysis presenting as mild heat illness in military training. Mil Med 1994;159:160-3.

13. Harris KM, Haas TS, Eichner ER, Maron BJ. Sickle cell trait associated with sudden death in competitive athletes. Am J Cardiol 2012;110:1185-8.

14. Oksenberg D, Dufu K, Patel MP, et al. GBT440 increases haemoglobin oxygen affinity, reduces sickling and prolongs $\mathrm{RBC}$ half-life in a murine model of sickle cell disease. Br J Haematol 2016. [Epub ahead of print]

15. Goldberg MA, Husson MA, Bunn HF Participation of hemoglobins $\mathrm{A}$ and $\mathrm{F}$ in polymerization of sickle hemoglobin. J Biol Chem 1977;252:3414-21.

16. Katch VL, McArdle WD, Katch FI, McArdle WD. Essentials of exercise physiology. Philadelphia: Wolters Kluwer/Lippincott Williams \& Wilkins Health; 2011.

17. Ferrone FA. The delay time in sickle cell disease after 40 years: a paradigm assessed. Am J Hematol 2015;90:438-45.

18. Hofrichter J, Ross PD, Eaton WA. Kinetics and mechanism of deoxyhemoglobin $\mathrm{S}$ gelation: a new approach to understanding sickle cell disease. Proc Natl Acad Sci USA 1974;71:4864-8.

19. Moffat K, Gibson QH. The rates of polymerization and depolymerization of sickle cell hemoglobin. Biochem Biophys Res Commun 1974;61:237-42.

20. Sunshine HR, Hofrichter J, Eaton WA. Gelation of sickle cell hemoglobin in mixtures with normal adult and fetal hemoglobins. J Mol Biol 1979;133:435-67.

21. Jensen FB. Red blood cell pH, the Bohr effect, and other oxygenation-linked phenomena in blood 02 and $\mathrm{CO} 2$ transport. Acta Physiol Scand 2004;182:215-27.

22. Eaton W, Hofrichter J. Hemoglobin S gelation and sickle cell disease. Blood 1987;70:1245-66.

23. Blinde MA, Russel S. Exertional sickling: questions and controversy. Hematol Rep 2014;6:66-70. 